\title{
Akalazya-Bir olgu sunumu nedeniyle
}

\author{
Achalasia (a case report) \\ Emel YAMAN ${ }^{1}$, Filiz EKȘI ${ }^{1}$, Altay KANDEMIR ${ }^{1}$, Murat TÖRÜNER², Selim KARAYALC̣IN², Ali ÖZDEN², Ayșe ERDEN³ \\ Ankara Üniversitesi Tıp Fakültesi, lç Hastalıkları Anabilim Dalı, Gastroenteroloji Bilim Dalı² ve Radyoloji Bilim Dalı, Ankara
}

\begin{abstract}
Akalazya nadir gözlenen bir özofagus motilite bozukluğudur. Katı ve sıvı gıdalara karşı yutma güçlüğü en sık semptomudur. Özellikle distal özofagus ve mide kardiya tümörleri ile klinik ve radyolojik olarak karışabilmektedir. Klinik olarak akalazyadan şüphenildiği durumlarda ilk yapılması gereken baryumlu özofagogram olup, manometrik çalışmalar ve üst gastrointestinal sistem endoskopik incelemeleri ile kesin tanı konulur. Tedavisinde balon dilatasyonu medikal yaklaşımlardan en etkili ve güvenilir olanıdır. Vakamız uzun süreli disfaji şikayetinin olması fakat tanıyı ancak 10 yıl sonra alabilmesi nedeniyle sunuldu ve literatür gözden geçirildi.
\end{abstract}

Anahtar sözcükler: Akalazya, disfaji.

Özofagus motilite bozuklukları klinikte en sık disfaji ve göğüs ağrısı şeklinde semptom verir. Katı gıdalara karşı olduğu kadar sıvı gıdalara karşı da intermitan ve non progresif disfaji gözlenir. Bazı hastalarda, anjina pektoris ile karışabilecek göğüs ağrısı olabilir (9). Özofagus motilite bozukluklarından şüphelenildiğinde baryumlu özofagogram, üst gastrointestinal sistem endoskopisi ve bazı durumlarda da manometrik incelemeler yapılmalıdır. Baryumlu ösefagografi, disfaji şikayeti ile gelen hastalarda ilk olarak yapılması gereken incelemedir. Mekanik obstruksiyonu ekarte etmek ve özofagus motilitesini değerlendirmek için oldukça faydalı bir metoddur. Üst gastrointestinal sistem endoskopisi, maligniteler başta olmak üzere mekanik obstruksiyon sebeblerini ekarte etmek için özellikle değerlidir. Disfajisi özofagusun inflamatuar hastalıklarına veya stenozuna bağlanamayan hastalar için, özofagus manometrik incelemeleri yapılmalıdır. Özofagus manometrik incelemelerine göre motilite bozuklukları dört ana başlık altında toplanabilir (9).
Achalasia is a rare esophageal motility disorder, with dysphagia to solids and liquids being the most common symptom. It can be confused with distal esophageal and gastric cardia malignancies. When this disorder is suspected, the first investigation should be barium esophagography, while the definite diagnosis is made by esophageal manometric measurements and upper gastrointestinal tract endoscopic series. Pneumatic dilation is the most effective and safest medical treatment approach. The present case is reported due to failure to diagnose the condition in spite of a ten year history.

Key words: Achalasia, dysfagia.

1. Alt özofajial sfinkterin gevşeme bozuklukları ile karekterize hastalıklar

a. Klasik akalazya

b. Atipik alt sfinkter gevşeme bozuklukları

2. Diffüz özofajial spazm

3. Özofagus hiperkontraksiyonu:

a. "Nutcracker" özofagus

b. İzole hipertansif alt özofagus sfinkteri

4. Özofagus hipokontraksiyonu: İnefektif özofagus motilitesi

Tüm özofagus motilite bozuklukları içerisinde belki de en iyi anlaşılmış olanı akalazyadır. Klasik akalazya, histopatolojik olarak myenterik pleksustaki nöronal inflamasyon ve nöron kaybı ile karekterize, sebebi bilinmeyen bir hastalıktır (9). Temel olarak özofagus gövdesindeki düz kaslarm relaksasyonundan sorumlu nitrik oksit üreten inhibitör nöronları etkiler. Klinikte distal $2 / 3$ özofagusta peristaltizm kaybı ve alt özofagus sfinkterinde relaksasyon kaybı izlenir. Semptomlar yavaş yavaş ortaya çıkar. Disfaji 
neredeyse tüm vakalarda gözlenir. Göğüs ağrısı, öksürük ve retrosternal yanma en sik izlenen diğer bulguları oluşturur (9). Kilo kaybı hastalığın geç dönemlerinde belirginleşir. Baryumlu özofagogram ve üst gastrointestinal sistem endoskopisinden sonra yapilan manometrik incelemelerde akalazya tanısının konulabilmesi için:

1. Alt özofagus sfinkterinin yetersiz gevşemesi

2. Simultane kontraksiyonlar veya aperista-ltizm ile karakterize özofagus kontraksiyonları

3. Artmış alt özofajial sfinkter basıncl $(45 \mathrm{mmHg}$ üstü)

4. Özofagus gövdesindeki dinlenim basıncinın mide dinlenim basıncından yüksek olması gerekir.

\section{OLGU}

Yaklaşık 10 yıldır önceleri sadece katı gıdalara karşı yutma güçlüğü şikayeti olan 33 yaşındaki hastaya (İ. Y) bu sürede başvurduğu doktorlar tarafından antiülser tedavi uygulanmış. Tedavilerle şikayetlerinde düzelme olmayan hastanın son bir yıldır sıvı gıdalara karşı yutma güçlüğü de ortaya çıkmış. Son 1 yılda 5-6 kilo kaybı olan hastamıza başvurduğu doktor tarafından baryumlu özofagogram incelemesi yapılmış ve mide kanseri olduğu söylenilmiş. Daha sonra özel bir doktora başvuran hastaya akalazya teşhisi konulmuş. Çelişkili teşhisler üzerine Ekim 2001'de hasta kliniğimize başvurdu. Yapılan baryumlu özofagus-mide -duodenum tetkikinde özofagus seyri boyunca geniş olarak izlenmekteydi. Distal kısmı tortuze görünümde, lümende gida artıklarına ve sekresyona bağlı dolma defektleri izlenmekteydi. Kontrast maddenin mideye geçişinde gecikme veya takılma izlenmedi. Tipik olarak mide havası izlenmedi. (Resim 1) Yapılan üst gastrointestinal sistem endoskopisinde özofagus mukozası normaldi. Lümende 12 saatlik açlığa rağmen gıda artıkları izlenmekteydi. Mide ve duodenum normaldi. Torakoabdominal tomografi incelemlerinde dilate özofagus dışında patoloji saptanmadl. Manometrik incelemede alt özofagus sfinkter dinlenim basinci $56 \mathrm{~mm} \mathrm{Hg}$ olarak saptandi. Yutkunmayla relaksasyon izlenmedi. özofagus gövdesinde dinlenim ortalama basıncı $22 \mathrm{mmHg}$, sslak yutkunmayla gövdede aperistaltik dalgalar ve simultane kontraksiyonlar
Tablo 1. Akalazya tedavisinde balonla dilatasyon.

\begin{tabular}{lcccc}
\hline Yazar & \multicolumn{2}{c}{ Başarl oranı } & \multicolumn{2}{c}{ Komplikasyon } \\
\hline KADAIKA & $27 / 29$ & $(93 \%)$ & yok & \\
ABID & $32 / 36$ & $(88 \%)$ & $3 / 36$ & $(6,6 \%)$ \\
ANSELMINO & $12 / 31$ & $(39 \%)$ & $8 / 55$ & $(14,5 \%)$ \\
PARKMAN & $108 / 123$ & $(88 \%)$ & $2 / 123$ & $(1,6 \%)$ \\
COCCIA & $12 / 16$ & $(75 \%)$ & YOK & \\
VAEZI & $14 / 20$ & $(70 \%)$ & YOK &
\end{tabular}

mevcuttu. Mide boşalma zamanı normal olarak ölçüldü. Birer hafta arayla toplam 2 seans balonla dilatasyon uygulanıldı. İşlem sonrası herhangi bir komplikasyon gelişmeyen hastanın yapılan kontrol baryumlu özofagogramında özofagus distal ucunda bir miktar dilatasyon saptand. (Resim 2,3,4) Şikayetlerinin gerilemesi üzerine hasta taburcu edilerek kontrole çağrıldı.

\section{TARTIŞMA}

Akalazya tedavisinde primer amaç, semptomların kaybı ve özofagus boşalmasinda düzelmedir. Bu amaçla anormal özofagus alt sfinkterini aşmak için cerrahi ve medikal bir takım teknikler kullanılır (4). Balonla dilatasyon, çoğu hastada en etkili ve güvenilir cerrahi dışı yaklaşımdır (1). Kısa dönemde başarı oranları son literatürlerde $85-90 \%$ olarak bildirilmektedir (2) (Tablo 1). Dilatasyon sonrası değerlendirmede baryumlu özofagogram en kolay uygulanabilir tekniktir. Şikayetlerinin kaybolduğunu belirten hastaların 30\%'unda özofaogram anormallikler gösterebilir. Balon dilatasyonu, daha önceden özofagus operasyonu geçirenlerde, dilate tortuz özofagusu olanlarda ve özofagus divertiküllü vakalarda daha zor olarak uygulanir (4). Sigmoid özofagusu olanlarda (çapı $8 \mathrm{~cm}$. den büyük olan) balonla dilatasyon uygulanıp uygulanmayacağı tartışma konusudur.

Balonla dilatasyon sonrası yapilan değerlendirmede semptomların devam etmesi durumunda tekrarlanabilir. Nitekim bizim hastamızda ilk seans sonrası şikayetlerde gerileme olmamıştı, ancak 2. seans sonrasında hasta katı gıdaları yutabildiğini ifade ediyordu.

İşlem sonrası remisyona girme yaşla ve postdilatasyon alt özofagus sfinkter basinci ile alakalıdır (7). Genç hastalarda (40 yaş altı) remisyon oranları daha düşük olarak 


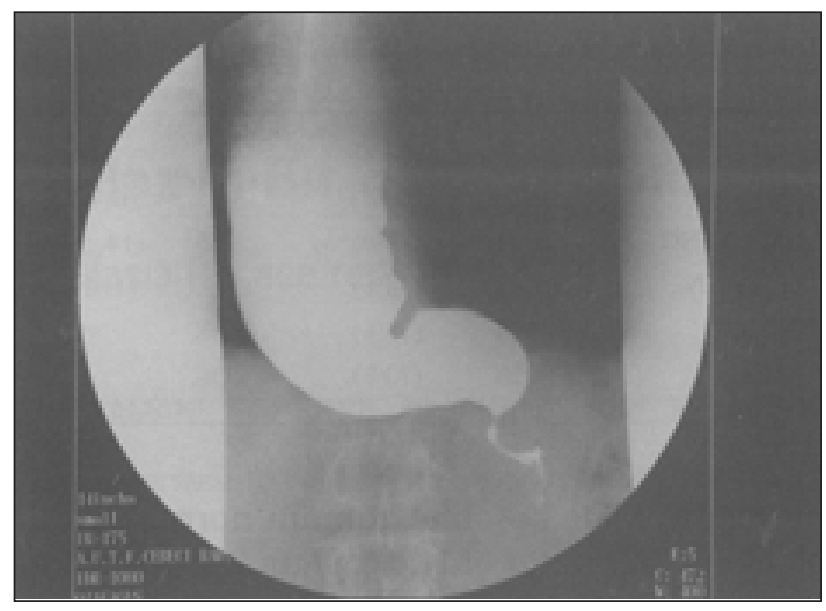

Resim 1. Dilatasyon öncesi

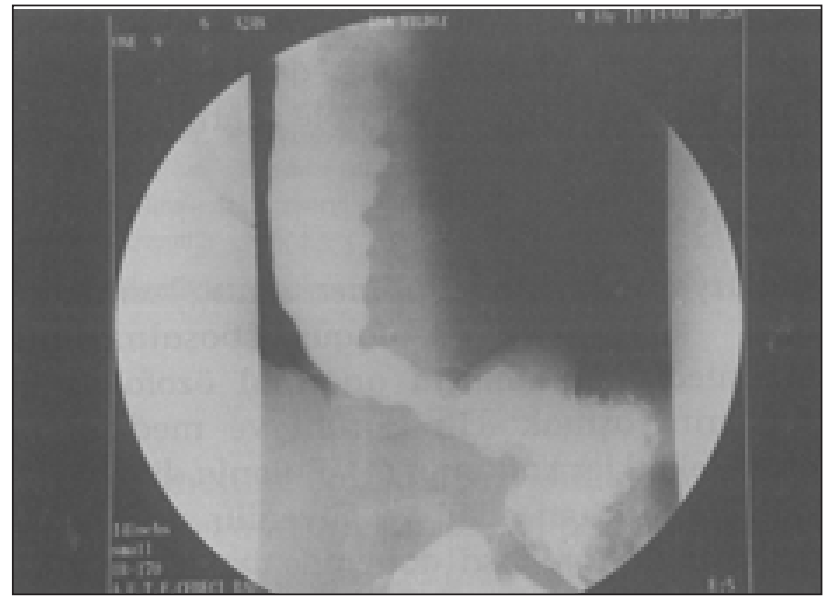

Resim 3. Dilatasyon sonrasi

bildirilmektedir. Tekrarlanan dilatasyonlar ile remisyona girme oranlarında belirgin ölçüde artma izlenmektedir. (3 dilatasyonla 1. yllda 89 $\%$ remisyon)

Balonla dilatasyon oldukça etkili, güvenilir ve ayaktan hastalarda da uygulanabilecek bir yöntemdir (5). En önemli dezavantajı 3-5 \% arasında değişen özofagus perforasyon riskidir. Perforasyonlar en sik olarak distal sol uçtan gerçekleşir ve işlem sonrası ilk saatlerde ağrı şeklinde kendini gösterir. Çoğunlukla parenteral

\section{KAYNAKLAR}

1. Koshy SS, Nostrant TT. Pathophysiology and endoscopic /balloon treatment of esophageal motility disorders. Surg Clin N Amer 1997; 971-92.

2. Pasricha JG, Kalloo AN. Recent advances in the treatment of acha-

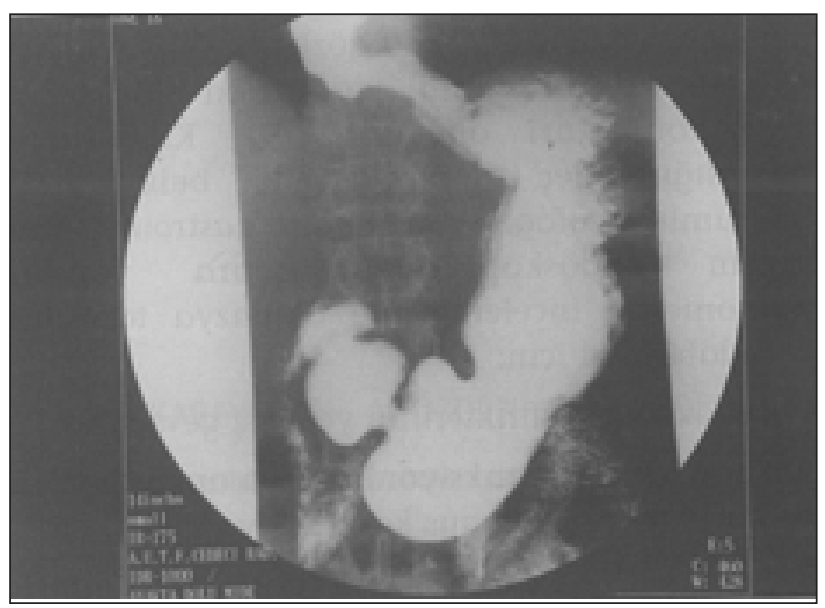

Resim 2. Dilatasyon sonrasi

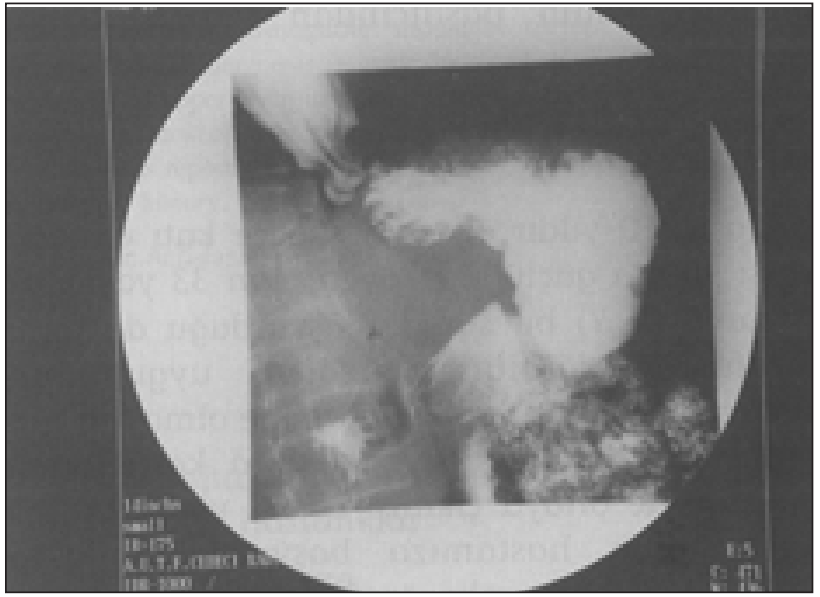

Resim 4. Dilatasyon sonrası

beslenmeye ve antibiyoterapiye iyi yanit verirler.

Diğer komplikasyonlar arasında intramural hematomlar, özofagus mukoza yırtıkları ve mide kardiyada divertikül oluşumu sayılabilir. Sanıldığının aksine dilatasyon sonrası reflü gelişme oranları sadece $2 \%$ lerde kalmaktadır (3). Bizim olgumuzdaysa her iki seans sonrasinda da herhangi bir komplikasyon gelişmemiştir.

Genel yaklaşım olarak 3 seans balonla dilatasyon uygulamasına rağmen remisyona girmeyen olgularda cerrahi yaklaşım planlanabilmektedir.

lasia. Gastrointest Endosc Clin namer 1997; 132: 233-40.

3. Shoenut JP, Duerksen D, Yffe CS. A prospective assesmant of gastroesophageal reflux before and after treatment of achalasia patients :Pneumatic dilation versus transthorasic limited myotomy. 
Am J Gastroenerol 92:1;109-12.

4. Abid S, Champion $G$, RichterJE, et al. Treatment of achalasia:The best of both worlds. Am J Gastroenterol 1994; 89: 979-85.

5. Ciarolla DA, Trube M. Achalasia. Short term clinical monitoring after pneumatic dilation Dig Dis Sci 1993;38:905-8.

6. Waring P, Falk GW. Endoscopic treatment of achalasia Breakout sesions 129-31.
7. Robertson CS. Choice of treatment for achalasia in relation to age Digestion $1988 ; 40: 224$.

8. Eckardt VF, Kanzler G. Complications and their impact after pneumatic dilatıons for achalasia :Prospective long term follow up study Gastroint Endosc 1992.

9. Spechler, Castell classification of oesophageal motility abnormalities. Gut 2001; 49: 145-151. 